\title{
A OCORRÊNCIA DA SÍNDROME DE BURNOUT NA EQUIPE DE ENFERMAGEM EM UTI
}

\section{THE OCCURRENCE OF BURNOUT SYNDROME IN THE NURSING TEAM IN ICU}

\section{Heline Gomes de Figueiredo}

Fisioterapeuta, Graduado pela Faculdade Presidente Antônio Carlos de Teófilo Otoni/MG, Brasil

Teresa Alves Lacerda Docente pela Faculdade Presidente Antônio Carlos de Teófilo Otoni/MG, Brasil

\section{Daniel de Matos Rodrigue}

Graduado em Jornalismo, Docente pela Faculdade Presidente Antônio Carlos de Teófilo Otoni/MG, pós graduado em Docência do Ensino Superior, Mestrando em Tecnologia, Ambiente e Socidade, Brasil E-mail: danielsmatos@bol.com.br

\section{Martha Honorato da Silva}

Enfermeira, Docente e Coordenadora pela Faculdade Presidente Antônio Carlos de Teófilo Otoni/MG, especialista em Programa de Saúde da Família, Urgência e Emergência, Brasil E-mail: marthahonorato@gmail.com

Franciny Souza Vieira Graduanda pela Faculdade Presidente Antônio Carlos de Teófilo Otoni/MG, Brasil E-mail: francinysouza9@gmail.com

\section{Resumo}

O estresse ocupacional é uma reação do organismo aos estímulos do meio, com componentes físicos e psicológicos causados pelas alterações psicofisiologicas que 
ocorrem quando o indivíduo se confronta com uma determinada situação. A síndrome de Burnout é um distúrbio psíquico é definida por Maslasch e Jackson (1981) como "uma reação à tensão emocional crônica gerada a partir do contato direto excessivo com outros seres humanos, particularmente quando estes estão preocupados ou com problemas". A dedicação exagerada à atividade por parte desse profissional é uma das características da síndrome. Na busca para um grau elevado de desempenho o portador de Burnout mede sua autoestima pela capacidade de realização e sucesso profissionais, e o que tem, no inicio, satisfação e prazer, termina quando esse desempenho não é reconhecido. Com isso, na necessidade de se afirmar, o desejo de realização profissional se transforma em obstinação e frustração. Este estudo tem como objetivo demonstrar e abordar a ocorrência da Síndrome de Burnout na equipe de enfermagem em Unidades de Terapia Intensiva U.T.I. Trata-se de um estudo de revisão da literatura, qualitativo, do tipo exploratório, pois proporciona maior familiaridade com o tema escolhido que foi desenvolvido através de pesquisa bibliográfica. As análises de dados colhidos em pesquisa bibliográfica apontam que a Síndrome de Burnout é causada por exaustão emocional relacionada ao estresse ocupacional. Como proposta de prevenção da síndrome de Burnout é necessário aumentar a variedade de rotinas no local trabalho, controlar o excesso de horas extras, investir no aperfeiçoamento profissional e motivar a equipe.

Palavras-chave: Estresse ocupacional; Síndrome de Burnout; Equipe de enfermagem.Separadas; Por; Ponto e vírgula.

\section{Abstract}

Occupational stress is a reaction of the organism to the stimuli of the environment, with physical and psychological components caused by psychophysiological changes that occur when the individual is confronted with a certain situation. For this type of professional life and death go hand in hand, making the professional becomes overworked and having to adapt to the means of work that are not always the right means established by the World Health Organization (WHO). With that the nurse stays with numerous disorders, plus a visible physical and emotional exhaustion. This stress can trigger the burnout syndrome. Syndrome is a mental disorder described by Freudenberger in 1974, an American doctor. The Burnout Syndrome is 
defined by Maslasch and Jackson (1981) as "a reaction to chronic emotional tension generated from excessive direct contact with other human beings, particularly when they are worried or troubled "". The dedication exaggerated activity by this professional is one of the characteristics of the syndrome. In the search for a high degree of performance the carrier Burnout measures her self-esteem by the ability to achieve and professional success, and that has, in the beginning, satisfaction and pleasure ends when this performance is not recognized. With this, the need to affirm the desire of professional accomplishment turns into frustration and futility. This study is an approach to burnout in nursing staff in order to address and demonstrate the occurrence of burnout syndrome in nursing staff in the Intensive Care Unit ICU. This study approaches burnout in the nursing team, with the objective of demonstrating and addressing the occurrence of Burnout Syndrome in the nursing team in Intensive Care Unit U.T.I. It is a qualitative, exploratory literature review study, which provides greater familiarity with the chosen theme that was developed through bibliographic research. As analyzes of data collected in bibliographic research indicate that Burnout Syndrome is caused by emotional exhaustion and occupational stress. As the proposal to prevent Burnout syndrome is necessary to increase the variety of routines in local work, control or exceed overtime, invest in professional development and motivate a team.

Keywords: Occupational stress; Burnout Syndrome; Nursing team.

\section{Introdução}

Atualmente a evolução econômica social e cultural é refletida diretamente no cotidiano das pessoas, devido ao avanço da globalização, trazendo como consequência uma exigência a mais no mercado de trabalho, fazendo com que as pessoas passem por um período de adaptação na nova correria do dia-a-dia.

No cotidiano, as pessoas buscam realizações no seu ambiente de trabalho para uma melhoria de vida tanto profissional como muitas vezes financeira em busca de condições de vida melhor. Segundo Silva (2000) os profissionais buscam cada vez mais essa interação com a sua profissão, pois devido a essa exigência, o profissional necessita ser mais eficiente, necessitando assim de um tempo maior de dedicação. 
Com tudo isso, o indivíduo fica em estado de tensão com medo de não conseguir suprir toda essa exigência que o mercado de trabalho está fazendo cada vez mais. Toda essa expectativa gera o estresse que está cada vez mais acometendo a população mundial. $O$ estresse é uma reação do organismo aos estímulos do meio, com componentes físicos e psicológicos causados pelas alterações psicofisiologicas que ocorrem quando o individuo se confronta com uma determinada situação (GUIMARÃES et al., 2007)

O processo de estresse possui três fases: a de alerta, a fase de resistência e a fase de exaustão. Como nenhum grupo profissional está isento dessas transformações, com a equipe de enfermagem não é diferente. A convivência com problemas estruturais, a falta de infraestrutura e a sobrecarga de trabalho, aliados à atenção que a instituição exige do seu papel profissional diante do usuário, deixa a enfermagem mais propicia ao estresse (COSTA, 2003; GOMEZ, 2005).

O estresse ocupacional está cada vez mais relacionado com a enfermagem e é causado pelo grande desgaste profissional, o enfermeiro com as responsabilidades em gerenciar uma equipe que está diretamente ligada com os seus clientes no processo de saúde e doença, e sabendo estabelecer confrontos emocionais pelos diversos tipos de clientes e de situações adversas (COSTA, 2003).

Para esse tipo de profissional a vida e a morte andam lado a lado, fazendo com que o profissional fique sobrecarregado de trabalho e tendo que se adaptar com os meios de trabalhos que nem sempre são os meios corretos estabelecidos pela Organização Mundiais de Saúde (OMS). Com isso o enfermeiro fica com inúmeros transtornos, além de um visível desgaste físico e emocional. Este estresse pode desencadear a Síndrome de Burnout. A palavra "burnout" significa "queimar-se por completo" e a síndrome é um distúrbio psíquico descrito em 1974 por Freudenberger, um médico americano.

A Síndrome de Burnout é definida por Maslasch e Jackson (1981) como "uma reação à tensão emocional crônica gerada a partir do contato direto excessivo com outros seres humanos, particularmente quando estes estão preocupados ou com problemas".

A dedicação exagerada à atividade por parte desse profissional é uma das características da síndrome. Na busca para um grau elevado de desempenho o portador de Burnout mede sua autoestima pela capacidade de realização e 
sucessos profissionais, e o que tem, no inicio, satisfação e prazer, termina quando esse desempenho não é reconhecido. Com isso, na necessidade de se afirmar, o desejo de realização profissional se transforma em obstinação e frustração.

Assim como várias profissões da área de saúde a enfermagem é considerada uma profissão que sofre impacto do stress proveniente do cuidado constante com as pessoas doentes e situações imprevisíveis. Proporcionando assim o aumento da probabilidade do desenvolvimento do estresse ocupacional na equipe de enfermagem em UTI.

Nesse sentido, o presente estudo busca entender por que a equipe de enfermagem em UTI estar propicia a desenvolver a Síndrome de Burnout.

Uma hipótese de que pode desencadear a Síndrome pressupõe-se que a baixa remuneração, a dupla jornada de trabalho, o stress ocupacional e más condições de trabalho causam esgotamento físico e emocional da equipe de enfermagem, em UTI o que contribui para o desenvolvimento da Síndrome de Burnout.

Nesse sentido esse artigo tem com objetivo demonstrar e abordar a ocorrência da Síndrome de Burnout na equipe de enfermagem em Unidades de Terapia Intensiva (UTI), identificar a ocorrência de Síndrome de Burnout no gênero feminino e masculino; em outro momento foi possível caracterizar a porcentagem da equipe de enfermagem que possui especialização em UTI.

\section{Revisão Bibliográfica}

\subsection{A HISTORIA DA ENFERMAGEM E AS DIFICULDADES DO SEU AMBIENTE DE TRABALHO}

O processo de cuidado pelos profissionais de enfermagem veio para o Brasil na década de 20 por Ana Nery, no Rio de Janeiro, onde trouxe uma verdadeira revolução. Estabeleceu os conceitos do que era o cuidado transformando assim a rotina dos cuidadores. Onde foi uma das fundadoras das primeiras escolas de enfermagem que teve inicio em 1923 (ROSSINI et al. 2007).

A escola de enfermagem teve grande importância durante um surto de varíola, as alunas prestaram cuidados a população e combate a doença. Com esse 
apoio das estudantes de enfermagem o índice de mortalidade da época baixou de $50 \%$ para $15 \%$ (ROSSINI et al., 2007).

$\mathrm{Na}$ década de 60 e 70 os profissionais de saúde enfrentaram muitas dificuldades para desenvolver o cuidado por não ter profissionais qualificados e sem experiência para a prestação dos serviços de saúde. Estes eram integrados aos meios religiosos, onde o bom profissional era aquele obediente às leis divinas $e$ seguidor das doutrinas religiosas (MUROFUSE et al., 2005).

Em relação a esses processos a enfermagem ainda se debate com as dificuldades em seu ambiente de trabalho e com más condições de executar o mesmo. Com o avanço da globalização e com a necessidade de diferentes cuidados devido aos diferentes tipos de pacientes, o trabalhador de enfermagem foi se tornando cada vez mais distante dos pacientes e dos próprios colegas de trabalho, como uma reação de defesa, desencadeando assim o stress ocupacional (ROSSINI et al., 2007).

\subsection{ESTRESSE}

O estresse é atualmente definido como uma reação do organismo com componentes físicos ou psicológicos que ocorrem quando a pessoa se confronta com uma situação que, de um modo ou de outro, vai causar algum desconforto psíquico ou físico para o individuo (GREENBERG, 2002).

O processo de estresse possui três fases: a primeira é a fase de alerta, em que $o$ individuo se prepara para as situações ameaçadoras e/ou difíceis. Nesta fase o estresse é positivo, pois acaba motivando a pessoa para encarar a situação. A segunda é a fase de resistência, o que seria o estresse moderado, em que o indivíduo se acostuma com o agente estressor tentando se adaptar e restabelecer o equilíbrio interno para retornar ao equilíbrio anterior. E a ultima é a fase de exaustão em que o individuo já não consegue manter e se adaptar naquele equilíbrio anterior frente a uma situação muito estressante, vivendo constantemente em estado de excitação nervosa (GREENBERG, 2002).

O estresse é subdividido em "mau" e "bom", chamados também de distresse e eustresse. $O$ distresse está relacionado com a monotonia e com a sobrecarga enquanto que o eustresse impulsiona o indivíduo para a solução de seus problemas. 
O stress não exerce influência somente sobre o indivíduo, repercute também nos aspectos culturais, sociais e econômicos. Muitas vezes, a falta ao trabalho, a baixa produtividade e acidentes podem ser decorrentes do stress (FRANÇA; RODRIGUES, 1997).

\subsection{ESTRESSE NA ENFERMAGEM}

A convivência com problemas estruturais, falta de infraestrutura e sobrecarga de trabalho, aliado à tensão de seu papel profissional e da instituição diante ao usuário, torna o profissional de enfermagem mais vulnerável ao estresse (COSTA, 2003; GOMEZ, 2005).

A enfermagem foi classificada pela Health Education Authority como a quarta profissão mais estressante no setor público, e vem tentando profissionalmente se afirmar para obter maior reconhecimento social (FERRAREZE, 2006).

Alguns componentes são conhecidos como ameaçadores ao meio ambiente ocupacional do enfermeiro, entre os quais o número reduzido de profissionais de enfermagem no atendimento em saúde em relação ao excesso de atividades que eles executam as dificuldades em delimitar os diferentes papéis entre os enfermeiros, técnicos e auxiliares de enfermagem e a falta de reconhecimento nítido entre o publico em geral em relação ao enfermeiro (MALAGRIS, 2006).

Além disso, a situação de achatamento de salários agrava a situação, obrigando os profissionais a ter mais de um vinculo de trabalho, resultando numa carga mensal extremamente longa e desgastante (MALAGRIS, 2006).

Foram identificados os elementos estressores de acordo com o cargo ocupacional dos enfermeiros: enfermeiros assistentes, recursos inadequados, atendimento ao cliente, relações interpessoais, carga emocional relacionada à assistência, cobranças, sobrecarga de trabalho, reconhecimento profissional, poder de decisão, questão salariais e carga horária. Os elementos estressores são comuns, independente da ocupação do enfermeiro, e refletem a cultura das causas e consequências que estes ocasionam no exercício da profissão, o que leva a novos desafios (FRANÇA; RODRIGUES, 1997).

Essa diversidade de situações sugere um quadro favorável ao estresse e também a Síndrome de Burnout que se origina através de um estado de prostração 
que leva o indivíduo ao esgotamento. Os autores referem-se ao fato de que o profissional de enfermagem não raramente manifesta uma espécie de desencantamento e cansaço que, frequentemente implicam uma situação de desesperança, falta de expectativa no trabalho e maior dificuldade no seu enfrentamento (ABRANCHES et al., 2006).

\subsection{DEPRESSÃO}

A depressão é uma doença "do organismo como um todo", que compromete o físico, o humor e, em consequência, o pensamento. A Depressão altera a maneira como a pessoa vê o mundo, entende as coisas e manifesta emoções, sente a disposição e o prazer com a vida. É uma doença afeta a forma como a pessoa se alimenta e dorme, como se sente em relação a si própria e como pensa sobre as coisas (VALADÃO et al., 2007).

Segundo Gonzáles (2006) existe certa semelhança entre a Síndrome de Burnout e a depressão; porém na síndrome de Burnout não tem a sintomatologia depressiva manifestada e o individuo continua fazendo as suas atividades diárias, mas a sua relação com o seu ambiente profissional e social fica prejudicada, pois a pessoa passa a ter um relacionamento mais frio, distante, e sem grande envolvimento afetivo, por não obter prazer nestas relações. Já síndrome da depressão é uma desordem afetiva que afeta vários aspectos da vida das pessoas.

Segundo Batista et al. (2004) a depressão pode ser desencadeada pela síndrome de Burnout, por isto não se pode confundir quando o individuo esta apenas deprimido, pois há outros sintomas específicos do Burnout envolvidos. Assim a síndrome de Burnout deve ser diagnosticada e tratada diferente do Estresse e Depressão.

\subsection{SÍNDROME DE BURNOUT}

O termo Burnout consiste em uma conjunção entre "burn" e "out", ambas as palavras da língua inglesa, onde a primeira significa "arder", "queimar". No entanto a segunda se refere a "fora", "para fora". Portanto, o significado literal para Burnout em português é "queimar para fora". No entanto, devido ao fato de Burnout ter se 
firmado como um termo internacionalmente reconhecido na literatura cientifica optou-se pela manutenção da nomenclatura original (MICHAELIS, 1989).

É uma síndrome que apresenta desgaste psicológico com características depressivas, levando ao esgotamento físico e mental intenso, estudado e definido por Herbert J.Freudenberger em 1974, cuja causa está intimamente ligada à vida profissional. (CARLOTTO, 2001)

Maslasch e Jackson (1984) definiram Burnout como uma síndrome psicológica causada por exaustão emocional, caracterizada por redução do tempo de profissão dos indivíduos que trabalham com as pessoas em diferentes situações ou capacidades.

A síndrome de Burnout estar relacionada ao estresse ocupacional que o profissional confronta em seu ambiente de trabalho definido em três dimensões: a exaustão emocional; a despersonalização; a insatisfação pessoal. Burnout é caracterizada como uma síndrome de esgotamento psicológico em consequência ao estresse relacionado ao seu ambiente de trabalho, devido ao contato direto e a diversidade de situações e de clientes envolvidos. Isto faz com que esse profissional perca o intuito e a vontade de trabalhar e se firmar profissionalmente, deixando de se interessar por suas obrigações e atribuições (CARLOTTO, 2001).

\subsection{HISTÓRIA DA SÍNDROME DE BURNOUT}

Freudenberger foi um dos primeiros estudiosos a estabelecer o conceito de Burnout que é a variação de perda de humor acompanhada de sintomas físicos e psíquicos em trabalhadores com diferentes especializações. Em 1980, Cherniss relatou que os profissionais que trabalhavam em setores onde os pacientes exigiam maiores cuidados, setores em que o profissional tem maiores responsabilidades administrativas, são os que têm maior probabilidade de desenvolver a síndrome de Burnout (CHERNISS, 1980).

O questionário Maslasch Burnout Inventory (MBI) foi criado por Malasch para melhor entendimento da síndrome foi estabelecido em fundamento da pesquisa de Freudenberger e foi traduzido em 1977 por Lautert os estudos foram revistos e analisados diversos casos na Espanha de onde tiraram uma linha de sintomas que facilitou o diagnostico do Burnout. Esses sintomas foram baseados na reação 
fisiológica que o nosso organismo manifesta após alguma situação estressante caracterizada por falta de apetite, cansaço, insônia, dor cervical, e ulceras; além de irritabilidade instantânea, gritos, ansiedades, depressão e frustração (CAMPOS, 2008).

No Brasil, Gomes e Rosa (2005) definem a associação diferenciada do Burnout em variáveis como sexo, estado civil e escolaridade relacionando o estresse e a qualidade de vida em enfermeiros, e salienta os fatores relacionados ao aparecimento da síndrome observados em um hospital em Porto Alegre.

\subsection{MASLACH BURNOUT INVENTORY (MBI)}

A psicóloga americana Cristina Maslach $(1981,1984,1986)$ despertou um interesse sobre a Síndrome de Burnout e desenvolveu pesquisas sobre a Síndrome e com isso percebeu que a despersonalização no ambiente de trabalho tem como consequência as reações estressoras, reação esta que é visível no profissional de enfermagem, em relação à pesquisa do medico americano Freudenberger. Para melhor entendimento da Síndrome Maslach criou junto com Susan Jackson em 1978 um questionário, o Maslach Burnout Inventory (MBI), sendo principal ferramenta para avaliação do nível da Síndrome de Burnout. A utilização do MBI está facilitando a detecção da Síndrome de Burnout, sendo essencial para a sua avaliação (MASLACH, 1993).

Sua Construção foi realizada em duas dimensões, a exaustão emocional e despersonalização, fazendo com que a terceira dimensão, a realização profissional, surgir-se no final de uma pesquisa em estudo de desenvolvimento com centenas de pessoas em um grande gama de profissionais (MASLACH, 1993).

Tendo como início a estrutura do $\mathrm{MBI} 47$ itens que foram organizados em uma amostra de 605 pessoas em profissões variadas. Dez fatores sobressaíram, e com isso por meio de uma avaliação criteriosa, foram eliminados seis deles, juntamente com mais 24 itens que não possuíam peso fatorial maior que 0,40. Mais tarde após uma nova amostra com 420 profissionais que possuíam a mesma variável do nível de profissionais da amostra anterior, com isso conluiou que os mesmos quatro fatores sobressaíram, sendo que três destes fatores apresentaram 
significados importantes (MALASCH; JACKSON, 1981; CORDES; DOUGHERTY, 1993; MORENO et al.1997).

O MBI foi criado somente para a avaliação do nível da Síndrome de Burnout, não levando em consideração os fatores antecedentes e as consequências de seus processos. O inventário de Malasch avalia os índices do nível de Burnout de acordo com escores de cada dimensão, sendo que altos escores em exaustão emocional e despersonalização e baixos escores em realização profissional, indicam alto nível de Burnout (MALASCH; JACKSONJ, 1986).

Em sua primeira versão o MBI tem como finalidade a avaliação da intensidade e a frequência das respostas de acordo com a escala de pontuação do tipo Likert, com as variedades de 0 a 6 (MASLACH; LEITER, 1997).

Um tempo depois em 1986 na segunda edição o MBI, passou a ter como critério de avaliação somente na frequência das dimensões que são: exaustão emocional, despersonalização e insatisfação pessoal (MASLACH; LEITER, 1997).

\subsection{CARACTERÍSTICAS DO BURNOUT}

No enfretamento de diversas situações, o individuo acaba tendo um desgaste emocional, sensação de perda de energia, fadiga ou combinações de sintomas psíquicos e físicos. Em consequência desses desgastes, o indivíduo manifesta reações, atitudes e respostas de desinteresse com as outras pessoas fazendo com que o profissional se isole dos outros, criando barreiras e distanciamentos. Essa reação é uma maneira de defesa em primeiro momento para adaptar-se a situação fazendo com que haja uma diminuição de tensão (GOMEZ, 2005).

Segundo Gomez (2005) o Burnout envolve três componentes: exaustão emocional; despersonalização e insatisfação pessoal.

QUADRO 1- Três componentes de Burnout

\begin{tabular}{|l|r|lr|}
\hline \multicolumn{2}{|c|}{ Exaustão Emocional } & Despersonalização & \multicolumn{2}{|c|}{ Insatisfação pessoal } \\
\hline é fundamental para a & é a fase em que o & fase em que o \\
síndrome de Burnout & profissional se isola de & profissional r vai \\
que tem como & tudo e de todos, se & desenvolver um meio de \\
\hline
\end{tabular}




\begin{tabular}{|c|c|c|}
\hline $\begin{array}{l}\text { característica a falta de } \\
\text { entusiasmo pelo o seu } \\
\text { ambiente de trabalho, } \\
\text { perda de energia, } \\
\text { cansaço que pode ter } \\
\text { como manifestações } \\
\text { físicas ou psíquicas ou } \\
\text { ambas que é } \\
\text { considerada uma fase } \\
\text { inicial da síndrome }\end{array}$ & $\begin{array}{l}\text { tornando uma pessoa } \\
\text { fria e distante, que é } \\
\text { vista como uma maneira } \\
\text { de defesa para evitar } \\
\text { maior agravamento é } \\
\text { onde o profissional pode } \\
\text { colocar toda a culpa de } \\
\text { sua falta de esperança } \\
\text { no paciente. }\end{array}$ & $\begin{array}{l}\text { defesa com as suas } \\
\text { atitudes e condutas essa } \\
\text { insatisfação pessoal } \\
\text { com os sentimentos de } \\
\text { competência e eficácia } \\
\text { do profissional na } \\
\text { realização do seu } \\
\text { trabalho }\end{array}$ \\
\hline
\end{tabular}

Fonte: Gomes (2005)

\subsection{EVOLUÇÃO DA SÍNDROME DE BURNOUT}

Segundo o Ministério da Saúde (Brasil 2001) a síndrome de Burnout apresenta um quadro evolutivo com quatro níveis de manifestação:

\begin{tabular}{|c|c|c|c|}
\hline 1º nível & $2^{\circ}$ nível & 3ํnível & $4^{\circ}{ }^{\circ}$ nível \\
\hline $\begin{array}{l}\text { Ocorre falta } \\
\text { de vontade, } \\
\text { ânimo ou prazer } \\
\text { de trabalhar, } \\
\text { dores nas costas } \\
\text { e coluna. }\end{array}$ & $\begin{array}{l}\text { Ocorre uma } \\
\text { deterioração no } \\
\text { relacionamento } \\
\text { com as pessoas. } \\
\text { Pode haver uma } \\
\text { sensação de } \\
\text { perseguição, } \\
\text { aumento } \\
\text { absenteísmo do } \\
\text { rotatividade de } \\
\text { empregos }\end{array}$ & $\begin{array}{l}\text { Ocorre notável } \\
\text { diminuição da } \\
\text { capacidade } \\
\text { ocupacional. } \\
\text { Podem começar } \\
\text { a aparecer } \\
\text { doenças } \\
\text { psicológicas } \\
\text { como alergias, } \\
\text { psoríase e picos } \\
\text { de hipertensão. O } \\
\text { individuo começa } \\
\text { a se automedicar } \\
\text { inicialmente em }\end{array}$ & $\begin{array}{l}\text { Caracterizado por } \\
\text { alcoolismo } \\
\text { droga dicção. } \\
\text { Ideais ou } \\
\text { tentativas de } \\
\text { suicídio podem } \\
\text { surgir e doenças } \\
\text { mais graves, tais } \\
\text { como câncer, } \\
\text { acidentes } \\
\text { cardiovasculares, } \\
\text { ente outros, } \\
\text { podem aparecer. }\end{array}$ \\
\hline
\end{tabular}




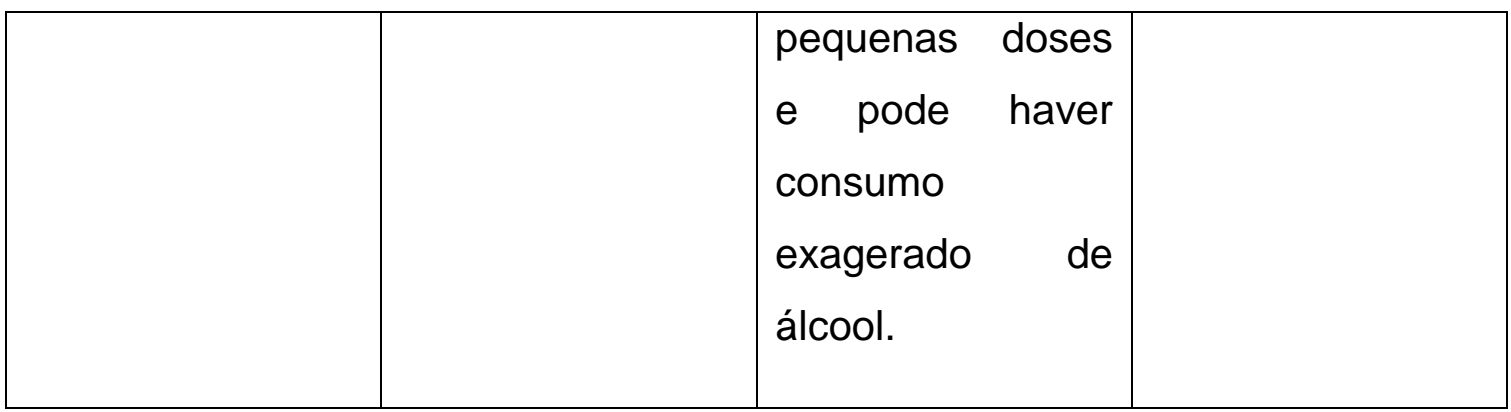

Fonte: Ministério da Saúde (2001)

Após ser observado o comportamento de diferenciação do profissional, é recomendado o afastamento do trabalho para melhor recuperação. Em período prévio não é recomendada a concessão de férias devido ao maior comprometimento da sua vida profissional (TEIXEIRA, 2007).

A síndrome de Burnout apresenta processos sintomáticos físicos, psíquicos, comportamentais e defensivos descritos por Barbosa, Beresin e Rossini et al (2007):

- Sintomas físicos: Caracterizados por fadiga crônica, apresentando desinteresse para realização de qualquer atividade mesmo sendo aquelas que antes seriam prazerosas para o individuo. Relacionada com o $1^{\circ}$ nível.

- Sintomas psíquicos: Caracterizados por desmotivação, com dificuldades de concentração e atenção, com desgaste emocional. Relacionada com 2ํㅡível.

- Sintomas comportamentais: Caracterizados por mostrar um profissional considerado "problemático" que não aceita mudanças e com quadro agressivo. Relacionado com 4ํㅡível.

- Sintomas defensivos: Caracterizados por mostrar um profissional que antes era comunicativo e que nesse quadro apresenta 0 inverso, 0 individuo acaba se isolando, com vontade de abandonar o trabalho. Relacionado com 3 nível.

\subsection{UNIDADE DE TERAPIA INTENSIVA U.T. I}

A Unidade de Terapia Intensiva (UTI) surgiu a partir da necessidade de recursos materiais e de profissionais especializados para 0 atendimento desses pacientes em estados crítico de saúde que corem risco iminente de morte, mas com possível recuperação onde esses precisam de um acompanhamento integral da equipe médica e da equipe de enfermagem centralizando os pacientes em um núcleo especializado (GOMEZ, 2005). 
A UTI é um setor que pode oferecer ambientes mais agressivo, tenso e traumatizante do hospital levando assim um comprometimento na saúde da equipe multiprofissional principalmente a enfermagem desse setor que lida com pacientes graves, isolamento, sofrimento tanto da família quanto do paciente e a morte (RAMONO, 1999).

Segundo Dejours et al (1992), a equipe multiprofissional lida com processo morte onde foi descrito por Elizabeth Kubler-Ross os cinco estágios desse processo de pacientes em estado terminal que são: negação, raiva, barganha, depressão e aceitação.

- Negação: O paciente nega o seu estado de saúde, desconfia da competência dos profissionais cuida dor, que pode ser temporário ou não pode durar até o fim.

- Raiva: é a fase onde o paciente se revolta por aquela situação "por que eu", não se conforma com seu estado de saúde.

- Barganha: é onde o paciente pode apoio Divino para sair do seu estado de doença fazendo promessas na troca da cura.

- Depressão: é onde o paciente sendo dificuldades do tratamento e dos grandes períodos de internação fazendo assim que a tristeza aumente, ocasionando a depressão.

- Aceitação: é quando o paciente aceita a sua situação o seu estado de doença.

\subsection{EQUIPE DE ENFERMAGEM EM U.T. I}

Os profissionais que trabalham em instituições hospitalares têm maiores probabilidades em desenvolver o Burnout por estarem em contente sofrimento não só com os pacientes, mas também com os seus familiares, pois esses profissionais trabalham direta e intensamente com os sofrimentos das pessoas, fazendo com que essas pessoas fiquem mais expostas aos distintos estressores ocupacionais (BENEVIDE-PEREIRA, 2000).

Segundo Teixeira (2007), os primeiros estudos de Burnout nos profissionais de enfermagem estão relacionados com: a dependência que os pacientes têm desses profissionais, a exigência emocional, a adaptação da instituição, baixos salários, alto nível de cobranças e aperfeiçoamento, além da exposição diária com o 
sofrimento e a maneira em lidar com a morte que às vezes é inevitável, tornando-se uma das profissões mais estressantes no setor público.

Devido à alta complexidade e da avaliação constante do cuidado e da monitorizarão de equipamentos que dão suporte a vida dos pacientes, a equipe de enfermagem passa a ter medo de acometer algum tipo de erro e acabar levando o paciente a óbito (ROMANO, 1999).

Pitta (1994), aborda aspectos relevantes que agrava a saúde desses profissionais dando mais ênfase a equipe de enfermagem do turno noturno, que possibilitam uma dupla jornada de trabalho em diferentes instituições o que é uma prática comum entre esses profissionais.

A UTI exige capacidade de atenção e concentração da equipe de enfermagem durante a assistência prestada das 24 horas do dia, durante os 7 dias da semana, incluindo a assistência no período da noite, finais de semana e feriados sem interrupção, períodos onde outros profissionais utilizariam para descanso, lazer e convívio social e familiar (TEIXEIRA, 2007).

Pitta (1994) aborda ainda a grande importância e a dificuldade em que a equipe de enfermagem lida no dia-a-dia da sua profissão a limitação do homem, a doença e a morte onde há fragilidade entre o racional e o emocional.

Devida a essa sobrecarga de tensões e de diferentes situações no seu ambiente de trabalho a equipe de enfermagem de UTI não é diferente ele tem grande vulnerabilidade ao Burnout (MASLACH; SHCAUFEL; LEITER, 2001).

Assim segundo Teixeira (2007), os primeiros estudos do Burnout nos a equipe de enfermagem esta relacionada coma a dependência que os pacientes têm desse profissional, a exigência emocional que o trabalho exige a adaptação da instituição, baixos salários, alto nível de cobranças e aperfeiçoamento, além da exposição diária com o sofrimento e a maneira em lidar com a morte que às vezes é inevitável, tornando-se uma das profissões mais estressantes no setor público. As situações e os agentes estressores na dia-a-dia da equipe de enfermagem que podem desencadear o Burnout são:

- A organização no trabalho: a falta de diálogo entre os colegas de equipe nas decisões do setor, conflito de ambiguidades de papéis, falta de recurso para trabalhar, falta de conhecimento do setor (pessoas novas no setor), mudanças constantemente da rotina, sobrecarga de trabalho. 
- Convívio profissional: a falta de entrosamento do enfermeiro com a equipe medica, falta do reconhecimento profissional, intrigas entre colegas de equipe levando a competitividade.

- Agentes físicos: ambiente com riscos químicos (medicamentos), biológicos (bactérias, fungos, vírus), físicos (ruídos), mecânicos (transporte de pacientes em maca).

- A vida pessoal: a dupla jornada com dificultem o convívio social e familiar.

- A atividade profissional: O convívio diário com os pacientes, e o sofrimento dos mesmos e de seus familiares, grande responsabilidade de estar prestando assistência em pacientes em estado grave.

\subsection{TRATAMENTO DO BURNOUT}

O Ministério da Saúde (BRASIL, 2001) preconiza o tratamento da síndrome com uma combinação que envolve psicoterapia e tratamento farmacológico, de acordo com a gravidade de cada caso especifico e com a indicação de cada recurso terapêutico. É de grande importância a psicoterapia para esse profissional devido ao desinteresse pela vida social causado pela síndrome. O uso de antidepressivo e medicamentos para insônia deverão ser controlados pelo profissional adequado (médico) e vale lembrar que a síndrome de Burnout é uma síndrome em que o profissional não consegue ter envolvimento com o seu trabalho e cabe ao medico restabelecer essa aproximação junto com o paciente (BRASIL, 2001).

\subsection{PREVENÇÃO DA SÍNDROME DE BURNOUT}

Segundo Philips (1984), a primeira medida para evitar a Síndrome de Burnout é ter conhecimento das suas manifestações. Torna-se essencial a conciliações das atividades profissionais com o lazer, não precisam fazer de suas vidas um campo de batalha, não permitindo que o estresse tome conta, procurando não se desgastar emocionalmente, afim de não entrarem em Burnout.

Algumas formas de prevenção como:

- Aumentar a variedade de rotinas, para evitar a monotonia;

- Prevenir o excesso de horas extras; 
- Dar melhor suporte social as pessoas;

- Melhorar as condições sociais e físicas de trabalho;

- Investir no aperfeiçoamento profissional e pessoal dos trabalhadores.

\section{RESULTADOS E DISCUSSÃO}

As análises de dados colhidos em pesquisa bibliográfica apontam que a Síndrome de Burnout é causada por exaustão emocional relacionada ao estresse ocupacional. Os estudos realizados por Mekler e Rezende (2007), em um hospital de São Paulo, abrangendo toda equipe de enfermagem, nos turnos manhã, tarde e noite, foram obtidos 19 participantes do sexo feminino totalizando $66 \%$ dos pesquisados e 10 participantes do sexo masculino o que representa $34 \%$ da população da equipe de enfermagem.

Figura 1- Porcentagem de profissionais classificados por sexo feminino e masculino

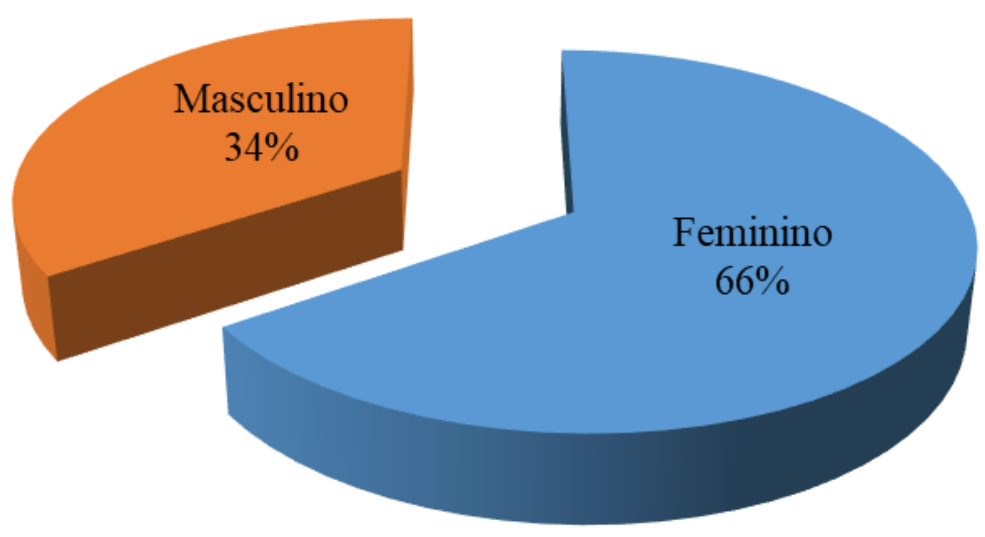

Fonte: Mekler e Rezende (2007)

Vale ressaltar esta variável pelo fato de ser analisado o adoecimento por gênero e por ser comum na profissão de enfermagem à prevalência do sexo feminino, fato este que pode estar relacionado ao cuidar, o que antigamente era inerente a mulher, com o sentimento maternal. 
De acordo com os dados pesquisados percebe-se que o sexo feminino tem mais facilidade em se envolver em situações de proximidade com o paciente. Tais diferenças podem ter uma explicação nos papéis socialmente aceitos. $O$ fato de as mulheres expressarem mais livremente suas emoções poderia vir a ser uma fonte de expressão de suas dificuldades e conflitos, aliviando os sentimentos de raiva, hostilidade e indignação, enquanto no sexo masculino estas emoções acabariam sendo expressas de forma inadequada depois de atingir um nível insuportável. A elevação da exaustão emocional no sexo feminino poderia também ocorrer pela dupla jornada de trabalho (a profissional e a do lar) a que a maioria está sujeita (BENEVIDES-PEREIRA, 2002).

Outro fator a considerar reside nas questões da relação histórica entre algumas profissões e gênero, uma vez que algumas são predominantemente masculinas, como a de policiais ou bombeiros, e outras femininas, como a docência ou enfermagem (MASLACH; LEITER, 1997).

Nos estudos de Mekler e Rezende (2007) foi estratificada a população por categoria profissional sendo que dos participantes 10 eram enfermeiros totalizando $35 \%$ e 19 eram técnicos de enfermagem o que totaliza $65 \%$ da população de estudo. Esses números entre enfermeiros e técnicos se devem ao fato de que o enfermeiro exerce função de coordenador de equipe, e na UTI adulto o dimensionamento destes profissionais é citado pela RDC no 7 na Seção III de Recursos Humanos, item III - Enfermeiros assistenciais: no mínimo 01 (um) para cada 8 (oito) leitos ou fração, em cada turno e no item $V$ - Técnicos de enfermagem: no mínimo um para cada dois leitos em cada turno, além de 1 (um) técnico de enfermagem por UTI para serviços de apoio assistencial em cada turno.

Figura 2- Porcentagens de números de profissionais classificados por especialidades enfermeiro e técnico 


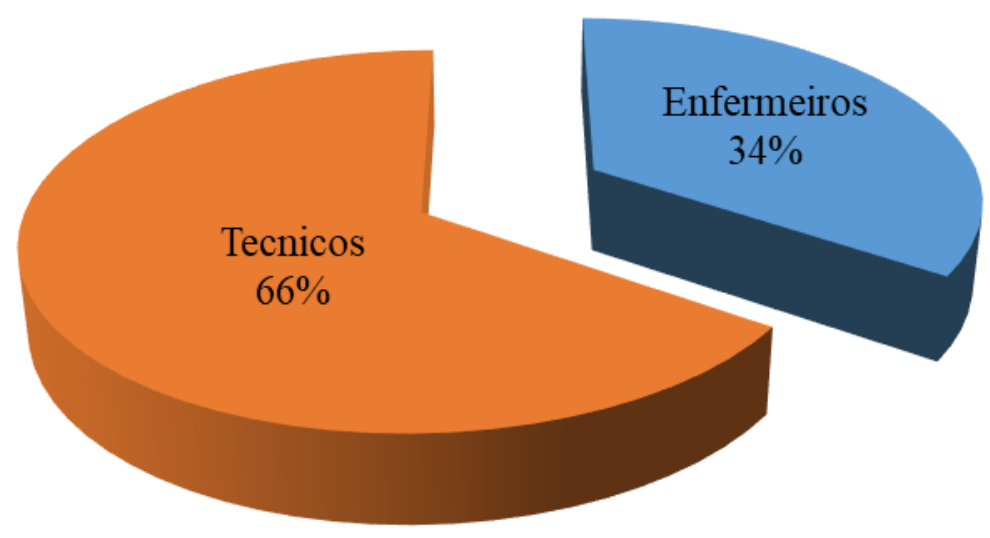

Fonte: Mekler e Rezende (2007)

A função do enfermeiro na UTI requer preparo adicional para desempenho deste cargo, nos estudos de Mekler e Rezende (2007) ao analisar a especialização especifica exigida para atuar nesta complexidade de atendimento, observou-se que entre os enfermeiros grande, parte possuem especialização, o que totaliza oito representando $80 \%$ da população e $20 \%$ o que representa dois enfermeiros, não possuem especialização. Mesmo tendo um número satisfatório, mais da metade dos profissionais possuem a especialização para atuarem nesta unidade de atendimento, preocupa-se ao mesmo tempo, pois por ser uma exigência legal o enfermeiro atuante em Unidade de Terapia Intensiva possuir a titulação de intensivista, como rege a resolução $\mathrm{n}^{\circ}$ 7, de 24 de fevereiro de 2010, dispõe sobre os requisitos mínimos para funcionamento de Unidades de Terapia Intensiva e dá outras providências.

Art. 13 Deve ser formalmente designado um Responsável Técnico médico, um enfermeiro coordenador da equipe de enfermagem e um fisioterapeuta coordenador da equipe de fisioterapia, assim como seus respectivos substitutos.§ 1ㅇ O Responsável Técnico deve ter título de especialista em Medicina Intensiva para responder por UTI Adulto; habilitação em Medicina Intensiva Pediátrica, para responder por UTI Pediátrica; título de especialista em Pediatria com área de atuação em Neonatologia, para responder por UTI Neonatal; $§ 2^{\circ}$ Os coordenadores de enfermagem e de fisioterapia devem ser especialistas em terapia intensiva ou em outra especialidade relacionada à assistência ao paciente grave, específica para a modalidade de atuação (adulto, pediátrica ou neonatal); $§ 3^{\circ}$ É permitido assumir responsabilidade técnica ou coordenação em, no máximo, 02 (duas) UTI (BRASIL, 2010, p.49). 
Figura 3- Porcentagem de profissionais com especialização em UTI

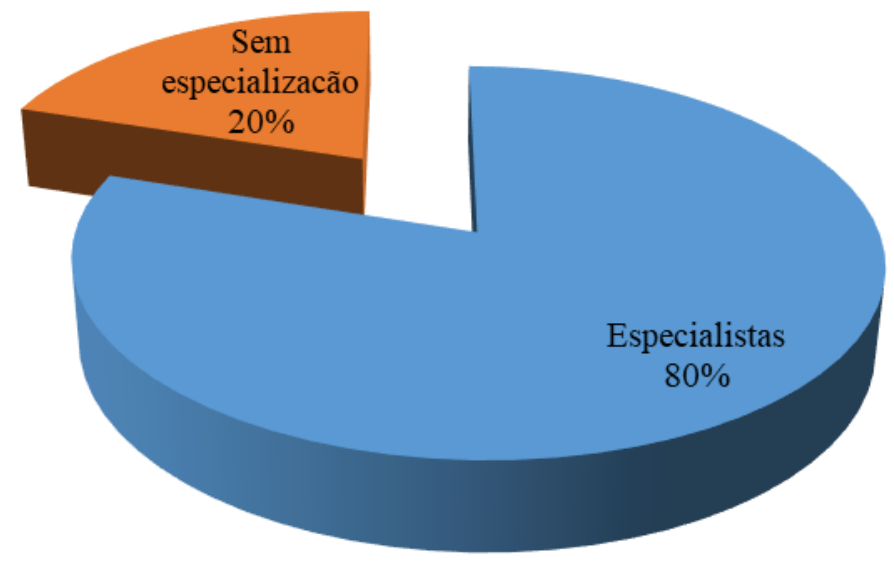

Fonte: Mekler e Rezende (2007)

Analisando a jornada de trabalho, identificou- se que 18 profissionais atuam apenas em um hospital o que representa $62 \%$, já os que atuam em mais de um hospital são 38\% totalizando11 profissionais. Dentro dessa profissão de Enfermagem e Técnico em enfermagem, é comum a jornada dupla das atividades que pode estar relacionado ao salário, ou outras situações, conforme a necessidade de melhoria de vida, fazendo com que estes profissionais trabalhem em mais de um hospital cinco trabalham 12 horas e seis profissionais trabalhem seis horas. 
Figura 4-Porcentagem dos profissionais que trabalham em um ou mais hospitais

- Trabalha em um Hospital $\quad$ Trabalha em mais de um Hospital

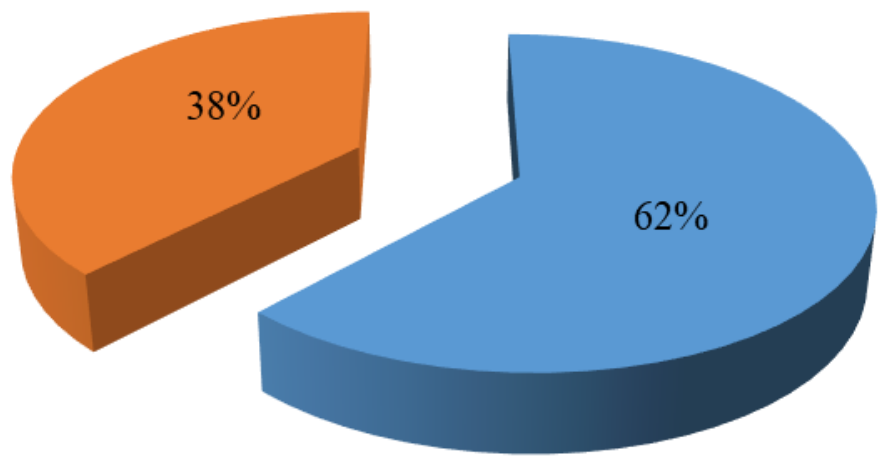

Fonte: Mekler e Rezende (2007)

Ao analisar os profissionais que tiram suas férias anuais, segundo Mekler e Rezende (2007) nos seus estudos encontraram 90\% dos profissionais que tiram férias anuais conforme o regimento da consolidação das leis trabalhistas, este total representa 26 profissionais. Já os que não tiram férias anuais representa 3 profissionais totalizando $10 \%$. Este fato pode esta relacionada a más condições financeiras fazendo com que esse profissional prefira optar pela venda de suas férias para ter um rendimento financeiro melhor no final do mês.

Figura5- Porcentagem de profissionais que tiraram ou não férias por ano.

- Tiram férias uma vez por ano

não tiram férias uma vez por ano

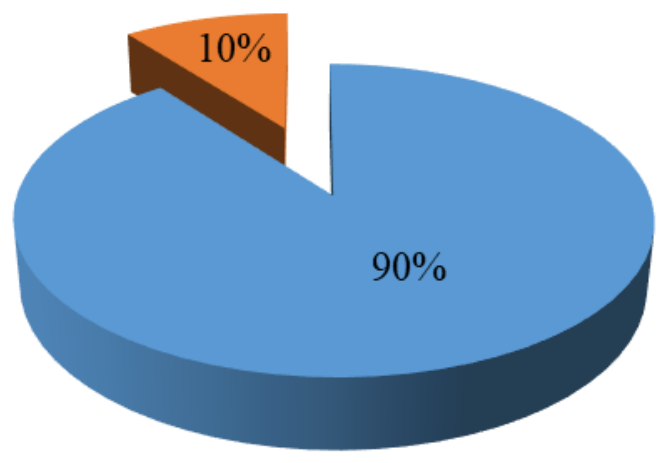

Fonte: Mekler e Rezende (2007) 
Foi apontado as variáveis que desencadeiam ou intensificam a 4 exaustão emocional no ambiente de trabalho, onde nos estudos de Mekler e Rezende (2007) cinco profissionais marcaram mais de uma opção, o que faz juz ao número total das alternativas marcadas. Sendo que a sobre carga de trabalho obtém o maior índice dos questionamentos totalizando $39,3 \%$ o que se refere a 11 profissionais a escolherem essa opção. A sobre carga de trabalha obtém o maior índice dos questionamentos totalizando 11 profissionais optaram por essa opção.

Figura 6 - Porcentagem dos participantes sobre a fonte de dificuldade.

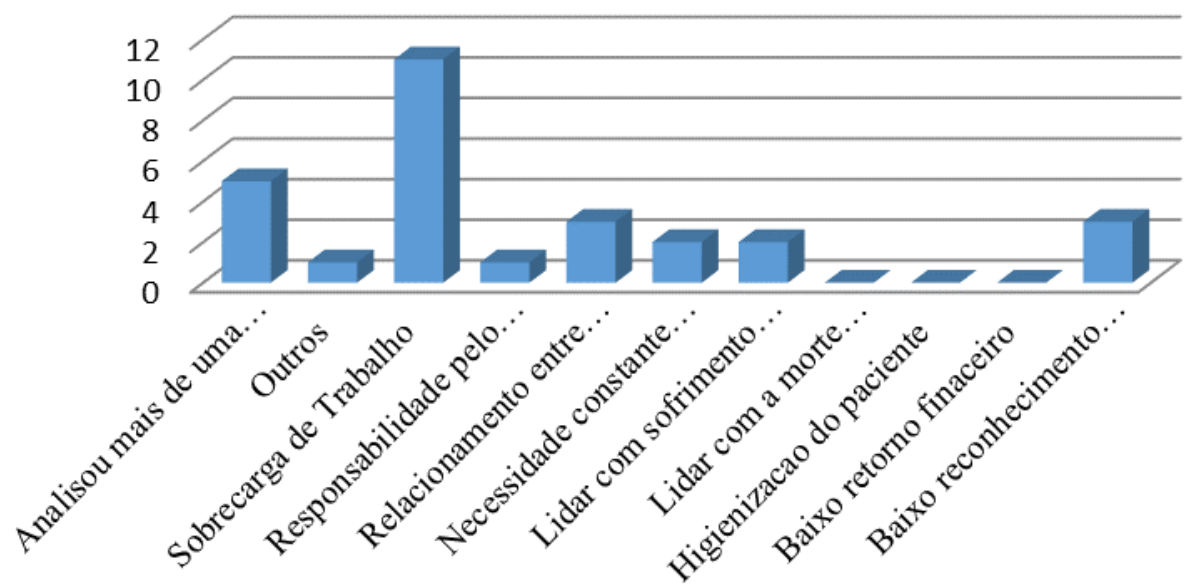

Fonte: Mekler e Rezende (2007)

Tabeça 1 - Porcentagem de profissionais em cada nível e dimensões

\begin{tabular}{lccc}
\hline & Exaustão Emocional & Despersonalização & $\begin{array}{l}\text { Realização } \\
\text { Profissional }\end{array}$ \\
\hline Alta & $66 \%$ & $10 \%$ & $17 \%$ \\
\hline Média & $17 \%$ & $42 \%$ & $24 \%$ \\
\hline Baixa & $17 \%$ & $48 \%$ & $59 \%$ \\
\hline Total & $100 \%$ & $100 \%$ & $100 \%$ \\
\hline
\end{tabular}

Fonte: Mekler e Rezende (2007) 
Ao analisarmos a tabela 01 , que é referente ao $\mathrm{MBI}$, onde são separado os itens de avaliação deste inventario para caracterizar a Síndrome de Burnout, percebe-se que no item exaustão emocional o com a variável Alta obteve-se $66 \%$ do total de participantes o que representa 19 profissionais e $10 \%$ para despersonalização da variável Alta, totalizando 3 profissionais e $17 \%$ para Realização Profissional na variável Alta totalizando 5 profissionais. De acordo com inventario de Malasch o grupo de profissionais estudados não apresentam alto índice da Síndrome de Burnout, pois com a combinação as três dimensões do nível considerado alto, pois apenas Exaustão Emocional está acima da metade dentre os pesquisadores.

A tabela 02 refere-se a junção das variáveis Alta e Média somatizadas, para que pudesse entender sobre a Síndrome de Brunout, referente aos sintomas, conforme estudos de Mekler e Rezende (2007).

Tabela 2 - Porcentagem de profissionais em cada dimensão com nível alto e média juntos

\begin{tabular}{lccc}
\hline & $\begin{array}{c}\text { Exaustão } \\
\text { Emocional }\end{array}$ & Despersonalização & $\begin{array}{c}\text { Realização } \\
\text { Profissional }\end{array}$ \\
\hline Alta Média & $83 \%$ & $52 \%$ & $41 \%$ \\
\hline Baixa & $17 \%$ & $48 \%$ & $59 \%$ \\
\hline Total & $100 \%$ & $100 \%$ & $100 \%$ \\
\hline
\end{tabular}

Fonte: Mekler e Rezende (2007)

Onde ao analisar as variáveis do MBI, percebe-se que a exaustão emocional obtém-se o maior índice de acometidos totalizando 24 profissionais e representando $83 \%$ da junção entre as variáveis, despersonalização com 15 profissionais acometidos totalizando $52 \%$ e realização profissional com $41 \%$ totalizando 12 profissionais acometidos.

Conforme discutido no gráfico 06, a equipe de enfermagem apresenta um elevado índice de exaustão, mesmo tendo uma realização profissional satisfatória além de apresentar um bom envolvimento profissional no trabalho.

Percebe-se através do estudo realizado que os hospitais poderiam adotar meios de prevenção para a Síndrome de Burnout através: do aumento na 
rotatividade no serviço, controle sobre o excesso das horas extras realizadas pela equipe de enfermagem; melhor remuneração e condições de trabalho além de investir no aperfeiçoamento profissional.

\section{Considerações Finais}

Entende-se que a Síndrome de Burnout é uma exaustão emocional relacionada ao estresse ocupacional descrita em 1974 pelo médico americano Freudenberger, cuja causa está intimamente ligada à vida profissional devido à dedicação exagerada pela atividade laboral.

O portador de Burnout mede sua autoestima pela capacidade de realização e sucessos profissionais. O desejo de realização profissional se transforma em obstinação e frustração quando o profissional não é reconhecido diante do trabalho realizado.

Para melhor abordagem no desenvolvimento da Síndrome de Burnout foi analisado um estudo de revisão bibliográfica em um hospital de São Paulo onde foi identificada maior prevalência na equipe de enfermagem da UTI, estando relacionado com: a dependência que os pacientes têm desses profissionais, a exigência emocional, a adaptação da instituição, alto nível de cobranças e aperfeiçoamento, além da exposição diária com o sofrimento e a maneira em lidar com a morte que às vezes é inevitável.

Como proposta de prevenção da síndrome de Burnout é necessário aumentar a variedade de rotinas no local trabalho, controlar o excesso de horas extras, investir no aperfeiçoamento profissional e motivar a equipe.

\section{Referências}

ABRANCHES, S.S; NAPOLEÃO, A. A. Reflexão sobre estresse e Burnout e a relação com a enfermagem. In : Revista Latino-Americana de Enfermagem.v.. 13, 02. Ribeirão Preto. Mar./ Apr. 2006.

BARBOZA,J,I,R,A; BERESIN, R. A síndrome de Burnout em graduados de enfermagem. Eisntein, v.5, n.3, p. 225-230, 2007. Disponível em <http://app,einstein,br/revistas/arquivos/PDF/599-eintein.5.3.1.portugues.225230.pdf.Acessado 21 maio de 2012. 
BATISTA, K. M; BIANCHI, E.R.F. Estresse do enfermeiro em unidade de emergência. Ver. Latino-Americana de Enfermagem, v. 14, n 4, p.534-539, jul/ago, 2006. Disponível em http://www.scielo.br/scielo. Acesso em 25 de set. 2012.

BENEVIDES-PEREIRA, A.M. Burnout; quando o trabalho ameaça o bem-estar do trabalhador. Minas Gerais: Casa do Psicólogo, 2012.

BENEVIDES-PEREIRA, A.M.T. O Estado da arte do Burnout no Brasil. O Estado da arte do Burnout no Brasil. Apresentado como Conferencia no I Seminário Internacional sobre Estresse e Burnout. Curitiba, 30 e 31 de agosto de 2002.

Revista Eletrônica InterAção Psy, ano 1, n.1,p.4-11, Ago 2003. Disponível em http://www.scielo.br/scielo. Acesso 21 maio de 2012.

BRASIL Ministério da Saúde (BR). Programa de Saúde da Família. Brasília (DF): Ministério da Saúde; 1994. Disponível em:

http://portal.saude.gov.br/portal/saude/default.cfm. Acesso 28 de abril de 2012.

BRASIL, Ministério da Saúde. Doenças relacionadas ao trabalho: Manual de procedimentos para os serviços de saúde. Capitulo 10 - Transtornos mentais e do comportamento relacionados ao trabalho. Serie A. Normas e manuais técnicos, $\mathrm{n}$ ㅇ 114. Brasília/DF: Ministério da saúde, 2001. Disponível em:

http://dtr2001,saude.gov.br/editora/produtos/livros/genero/livros.htm\#d. Acessado 13 de março de 2012.

CAMPOS, Helton R. Noções de psicometria. In: FUENTES, D; MALLOY-DINIZ, Leandro F; CAMARGO, Cândida H. Neuropsicologia teoria e pratica. Porto Alegre: Artmed. 2008.

CARLOTTO, M, S. Síndrome de Burnout: um tipo de estresse ocupacional, 2001, Porto Alegre, v. 37, n. 1 p.57.

COSTA, J.R; LIMA, J.V; ALMEIDA, P.C. Estresse no trabalho do enfermeiro. Rer. Esc.Enferm. USP. V. 13, P.63-71, 2003. Disponível: http://www.scielo.br/scielo.

COSTA,J.C.; LIMA,R .A.G.Luto da equipe: revelações dos profissionais de enfermagem sobre o cuidado a criança/adolescente no processo de morte e morrer. Rer. Latino-Am. Enfermagem, v.13, n.2, Ribeirão Preto, Mar./Apr. 2005. Disponível em <http://www.scielo.br/scielo>. Acesso 20 maio de 2012.

DEJOURS, M,S. (1992). Síndrome de Burnout: um tipo de estresse ocupacional. Canoas: ULBRA. Acesso 13 out de 2012.

DIAS, J. T. burnout: um indicador sem uma teoria em estudo exploratório das possíveis psicossociais para a compreensão do esgotamento emocional no trabalho. Tese de Mestrado pel PUC-MG, 2003.

FASCINA, L. P; GUIMARÃES, C.P.A; KAREN, S. H; MEKLER, P.L REZENDE, F. Avaliação do nível da Síndrome de Burnout na equipe de enfermagem da UTIadulto. 28p. (dissertação de graduação) São Paulo 2007. 
FERRAREZE, N.L; SCHER, M; MUINOS, R. Um instrumento para avaliação de estressores psicossociais no contexto de emprego. Psicologia Reflexão Critica, Vol. 14, № 3, 2006. Disponível em: http://www.scielo.br/scielo. Acesso em 17 Set 2012.

FRANÇA ACL, RODRIGUES AL. Stress e trabalho: uma abordagem psicossomática. São Paulo (SP): Atlas; 1999.

GOMEZ, M.M.N.et al. Relacion entre perfil psicológico, calidad de vida estrés assistencial em personal de enfermaria. Univ. Psychol. Bogotá, V .4. N.1, 2005. Disponível em. http://pepsic.bvs-psi.org.br/scielo. Acesso 20 maio de 2012.

GRENBERG, G.P;. A qualidade de vida e sintomas depressivos em residentes de enfermagem. Rev. Latino-am. Enfermagem, Ribeirão Preto, v. 13, n. 2, mar./abril,2002.. Disponível em <http//www.scielo.br/scielo>. Acessado em 12 Set 2012.

GUIMARÃES, L. A. M. Atualizações sobre a síndrome de burnout (online). 2007. Disponível na web: <htt://www.debas.faenquil.br/BURNIUT-editado.doc>(Caderno Universitário) Canoas: ULBRA. Acesso 13 março de 2012.

MALAGRIS, L.M.N; FLORITO, A.C.C. Avaliação do nível de estresse de técnicos da área de saúde. Estudos de Psicologia. V.23 n.4; 2006. Disponível em <http//www.scielo.br/scielo.br/ scielo> Acessado em 30 Set 2012.

MASLACH, C,; SCHAUFELI, W. B.\& LEITER, M, P, Job Burnout. In: Annu. Rev. Psychol. 52, 397-422, 1997.

MASLACH, C., \& JACKSON, S E. The measurement of experienced burnout. 1994, Disponível em: http://www.revispsi.uerj.br/v2n2/artigos/artigos/artigo8. Acesso de 15 de maio de 2012.

MUROFUSE, N. T; ABRANCHES, S. S.; NAPOLEÃO, A. A. Reflexões sobre estresse e Burnout e a relação com a enfermagem. Rer . Latino- am Enfermagem 2005, março-abril; 13(2):255-61. Disponível em: http://www.scielo.br/scielo. Acesso 28 abril de 2012.

ORGANIZAÇÃO MUNDIAL DE SAUDE - OMS. Perspectivas da doença em um mundo globalizado. 2007. Disponível

http://portal.saude.gov.br/portal/saude/default.cfm.. Acesso 12 maio de 2012.

PHILIPS,J.R.1984.Faculty Burnout.American Journal of Nursing,(9):1525-1526. PITTA, A. Hospital: dor e morte como oficio. São Paulo: Hucitec, 1994.

ROMANO, B. W. Princípios para a pratica da psicologia clinica em hospitais.Revista latina americana de enfermagem. V. 13, n.02. Ribeirão Preto. Mar/ Apr . Síndrome de 1999.

ROSA, C.; CARLOTTO, M.S. Síndrome de Burnout e satisfação no trabalho em profissionais de uma instituição hospitalar. Rer. SBPH, v.8, n.2, Rio de Janeiro 
dez.2005. Disponível em : http://pepsic.bvs-psi.org.br/scielo.php/script_sci_serial. Acesso 11 maio de 2012.

ROSSINI, A.B.; CONCATO; J.T.; BESSANE, A.A. Revisão de literatura sobre as causas da síndrome de Burnout em profissionais de enfermagem. Revista de Enfermagem da UNIANDRADE, 2007. Disponível em:

www.uniandrade.edu.br/links/menu3/publicacoe/revista_enfermagem/artigo082.pdf Acesso 20 março de 2012.

SILVA, F.P.Burnout: Um desafio a saúde do trabalhador. Revista da UFSJ, v.2,n.1, jun,2000. Disponível

http://www.eletrica.ufsj.edu.br/pub/pat/Textos\%20seminarios/desafio\%20a\%20saude \%20do\%20trabalhador.doc. Acesso 14 maio de 2012.

SALOMAO, P. E. A. et al. As Tecnologias de Informação e Comunicação (TIC) no ensino superior. Revista Multidisciplinar do Nordeste Mineiro, v. 1, 2018.

TEIXEIRA, M .O Burnout e os enfermeiros . Saúde mental e psiquiátrica.

Publicado em 2007. Disponível em: http://br.monografias.com/trabalhos3/burnoutenfermeiros/burnout. Acesso 12 de maio de 2012.

VALADÃO, C .L . Pratica psicologica em UTI- uma analise contextual. In: GUILHARDI, H,J; et al . Sobre comportamento e cognição: expondo a variabilidade. 1ํㅡㄹ. E. V. Santo Andre, SP : ESET ec Editores Associados, 2006.

VIEIRA, I; RAMOS, A; MARTINIS. D. Burnout BA clinica psiquiátrica: relato de um caso. Rer. Psiq. Rio GR. Sul, v.28, n.03, p.352-366, set/dez,2006. Disponível em http://wwww.scielo.br/scielo. Acesso 01 de junho de 2012. 